\title{
ANALISIS NILAI AQIDAH PADA NOVEL SURGA YANG TAK DIRINDUKAN KARYA ASMA NADIA
}

\section{Dones Arice}

The purpose of this research is to describe the use of Aqidah value in the novel Surga yang Tak Dirindukan by Asma Nadia. This research is descriptive qualitative research. The primary data is written data in a form of quotations that contain Aqidah value in the novel Surga yang Tak Dirindukan by Asma Nadia. The data is collected by using libarary study and documentation technique which focuses on analyzing the Aqidah value in the novel. The technique of analysis data is descriptive analysis.

The result of this research concludes that the Aqidah values are represented in the quotes of the novel Surga yang Tak Dirindukan by Asma Nadia. The most dominant aspect is the aspect of belief to Allah SWT.

\section{PENDAHULUAN}

Karya sastra sebagai potret

kehidupan bermasyarakat merupakan

hasil ciptaan atau kreasi manusia yang

memiliki nilai keindahan (estetis)

yang dapat dinikmati, dan dipahami,

oleh masyarakat. Karya sastra tercipta

karena adanya pengalaman batin

pengarang berupa peristiwa atau

problem dunia yang menarik. Karya

sastra memunculkan gagasan imajinasi

yang dituangkan dalam bentuk tulisan.

Karya sastra menyumbangkan tata

nilai figur tatanan masyarakat, hal ini sastra dengan masyarakat, walaupun karya sastra tersebut berupa fiksi, namun pada kenyataannya, karya sastra juga mampu memberikan manfaat yang berupa nilai-nilai moral bagi pembacanya. Karya sastra selalu menampilkan gambaran hidup dan kehidupan itu sendiri yang merupakan kenyataan sosial.

Karya sastra sangat bermanfaat bagi kehidupan, mengungkapkan tentang nilai kebenaran-kebenaran hidup, yang dapat memberikan kesadaran kepada pembaca. Karya merupakan timbal balik antara karya Analisis Nilai Aqidah Pada Novel Surga Yang Tak Dirindukan Karya Asma Nadia 
sastra dapat memberikan kegembiraan

dan kepuasan batin, karena siapa pun

bisa menuangkan isi hati dan pikiran

dalam sebuah tulisan yang bernilai

seni. Karya sastra terdiri dari berbagai

jenis di antaranya puisi, prosa dan

drama. Prosa sebagai karya sastra

yang memiliki jenis di antaranya

novel.

Novel merupakan bentuk karya

sastra yang paling populer di dunia.

Karya sastra ini paling banyak

beredar, lantaran daya kamonukasinya

yang luas pada masyarakat. Novel

tercipta disebabkan dari reaksi

terhadap suatu keadaan yang

menggambarkan realitas sosial dalam

masyarakat yang mengandung nilai

kehidupan. Maka dari itu, novel

menggambarkan kehidupan manusia

pada umumnya, lengkap dengan lika-

liku persoalan yang melingkupinya

sesuai dengan kodrat. Meskipun tidak semua manusia mengalami persoalan

dan permasalahan, hal ini tetap harus

dilalui karena fitrahnya sebagai

makhluk Tuhan. Dalam sebuah novel

dapat ditemukan nilai-nilai religius

yang terkandung di dalamnya.

Nilai-nilai religius yang

terkandung dalam novel dimaksudkan

agar penikmat novel tersebut

mendapatkan renungan batin dalam

kehidupan yang bersumber dari

agama. Nilai religius merupakan nilai

kerohanian tertinggi dan mutlak serta

aqidah atau keyakinan merupakan

landasan pokok bagi orang yang

beragama.

Aqidah dapat diibaratkan

perjanjian yang kokoh yang tertanam

jauh di dalam lubuk hati sanubari

manusia. Aqidah merupakan

keyakinan keagamaan yang dianut

oleh manusia dan menjadi landasan

segala bentuk aktivitas, sikap, Analisis Nilai Aqidah Pada Novel Surga Yang Tak Dirindukan Karya Asma Nadia 
pandangan dan pegangan hidup.

Aqidah inilah yang memberi jawaban atas pertanyaan terhadap hakikat kehidupan, serta pertanyaan yang lain tentang makna kehidupan dan alasan di baliknya. "Dalam pengertian lengkapnya, aqidah merupakan suatu kepercayaan dan keyakinan yang menyatakan bahwa Allah SWT adalah Tuhan yang Maha Esa, Ia tidak beranak dan tidak diperanakan dan tidak ada sesuatupun yang menyerupaiNya” (Aziz, 2013:7).

Tidak sedikit novel yang mengisahkan tentang nilai aqidah di dalamnya seperti novel Surga Yang Tak Dirindukan karya Asma Nadia.

Tujuan penelitian merupakan arah dalam suatu penulisan. Tujuan penelitian haruslah jelas mengingat penelitian harus mempunyai tujuan dan sasaran yang tepat. Berdasarkan latar belakang dan rumusan masalah di atas tujuan penelitian ini adalah untuk mendeskripsikan nilai aqidah yang terdapat di dalam novel Surga Yang Tak Dirindukan karya Asma Nadia.

\section{STUDI KEPUSTAKAAN}

Aqidah merupakan ikatan atau keyakinan. Ikatan dalam pengertian ini merujuk pada makna dasar bahwa manusia sejak azali (dahulu) telah terikat dengan satu perjanjian kuat untuk menerima dan mengakui adanya sang pencipta yang mengatur menguasai dirinya, yaitu Allah SWT.

Aqidah secara etimologis (lughatan), aqidah berakar dari kata 'aqada-ya'qidu 'aqdan-'aqidatan. 'Aqdan berarti simpul, ikatan, perjanjian dan kokoh. Setelah bertemu menjadi 'aqidah berarti keyakinan. Relevansi antara arti kata 'aqdan dan 'aqidah adalah keyakinan itu tersimpul dengan kokoh di dalam hati, bersifat mengikat dan mengandung perjanjian (Ilyas, 1993:1). 


\section{Aspek-aspek Aqidah}

Sistem kepercayaan Islam atau aqidah biasanya dibangun mengikuti sistimatika arkanul iman atau yang lazim disebut rukun iman yang meliputi, keimanan kepada Allah SWT, para malaikat, kitab-kitab Allah, para Rasul, hari kiamat, serta Qadha dan Qadar-Nya. Berikut ini adalah uraian mengenai Rukun Iman.

\section{Iman Kepada Allah}

Iman kepada Allah berarti percaya akan adanya Allah. "Esensi iman kepada Allah SWT adalah Tauhid yaitu mengesakan-Nya, baik dalam zat, asma' wa shifat, maupun af al (perbuatan-Nya)" (Ilyas, 1993: 18).

\section{Iman Kepada Malaikat}

$$
\text { Malaikat adalah makhluk }
$$
ghaib diciptakan oleh Allah SWT. Sebagai makhluk ghaib wujud malaikat tidak bisa dilihat, didengar, diraba, dicium dan dicicipi (dirasakan) oleh manusia atau dengan kata lain tidak bisa dijangkau oleh panca indera. "Secara etimologis kata Mala$i k a h$ (dalam bahasa Indonesia disebut malaikat) adalah bentuk jamak dari malak, berasal dari mashdar al-alukah artinya ar-risalah (misi,pesan).

\section{Iman Kepada Kitab Allah}

$$
\text { "Secara terminologis yang }
$$

dimaksud dengan Kitab (Al-Kitab, Kitab Allah, Al-Kutub, Kitab-kitab Allah) adalah Kitab Suci yang diturunkan oleh Allah SWT kepada para Nabi dan RasulNya" (Ilyas, 1993:122).

\section{Iman Kepada Para Nabi dan}

\section{Rasul Allah}

Nabi dan Rasul adalah manusia biasa, ia laki-laki yang dipilih oleh Allah SWT untuk menerima Wahyu, yang diiringi dengan Analisis Nilai Aqidah Pada Novel Surga Yang Tak Dirindukan Karya Asma Nadia 
kewajiban menyampaikan atau

membawa suatu misi tertentu.

\section{Iman Kepada Hari Kiamat}

Hari kiamat sering juga disebut sebagai hari akhir. Yang dimaksudkan dengan hari akhir ialah kehidupan yang kekal sesudah kehidupan di dunia yang fana ini berakhir, termasuk proses dan peristiwa yang terjadi pada hari itu.

\section{Iman Kepada Qadha dan Qadar}

Allah

Qadha dan Qadar sering juga disebut dengan istilah Takdir. Takdir merupakan segala ketentuan, undangundang, peraturan dan hukum yang ditetapkan secara pasti oleh Allah SWT untuk segala yang ada.

\section{METODOLOGI PENELITIAN}

Metode penelitian merupakan cara yang diperlukan oleh seseorang peneliti agar dapat mendukung dan Analisis Nilai Aqidah Pada Novel Surga Yang Tak Dirindukan Karya Asma Nadia menentukan keberhasilan sebuah penelitian. Metode juga merupakan cara memahami untuk menjadikan sasaran penelitian yang digunakan oleh peneliti. "Metode adalah cara yang digunakan peneliti untuk memecahkan masalah yang diteliti” (Siswantoro, 2010:56).

Metode penelitian memegang peranan penting untuk mencapai tujuan dari kegiatan penelitian. ”Oleh sebab penelitian merupakan kegiatan ilmiah, metode harus sistematis atau prosedural. Sistematis artinya seorang peneliti harus bekerja secara teratur di dalam upaya memecahkan masalah. Ia tidak bisa bergerak dari satu aspek atau fase ke aspek atau fase lain secara serampangan" (Siswantoro, 2010:56).

Jadi metode penelitian merupakan cara yang digunakan seorang peneliti dalam sebuah penelitian ilmiah dengan cara 
mengumpulkan, mengelolah,

menganalisa, dan menyajikan data

dalam sebuah penelitian karya sastra.

"Metode penelitian sastra adalah cara

yang dipilih oleh peneliti dengan

mempertimbangkan bentuk, isi, dan

sifat sastra sebagai objeknya"

(Endraswara: 2013:8).

HASIL PENELITIAN DAN

PEMBAHASAN

\section{Kutipan-kutipan tentang Iman}

kepada Allah dalam novel Surga

Yang Tak Dirindukan karya Asma

Nadia.

"Pras, seperti juga dirinya, bisa bertemu kematian kapan saja.

Hanya Allah yang

tahu. Itu berarti Arini akan menjalani harihari sendiri, tanpa pangeran yang sebelumnya

melengkapi. Siapkah?

Ketika hari $\mathrm{H}$ tiba,

Arini bertekad

membuang jauh-jauh kekhawatirannya"

(SYTDR: 45).

Kutipan di atas menunjukkan bahwa Arini meyakini akan ketetapan Allah termaksud takdir kematian seseorang. Sebagai hamba Allah yang taat Arini percaya karena siapun bisa bertemu kematian kapan saja. Arini bertekad membuang jauh-jauh kekhawatirannya untuk ditinggalkan jika ajal Pras telah sampai pada waktunya.

\section{Kutipan-kutipan tentang}

Iman kepada Kitab Allah dalam novel Surga Yang Tak

Dirindukan karya Asma Nadia.

"Poin Luki Hidayat semakin bertambah di mataku dari pertemuan satu ke pertemuan lain. Dan perbedaan yang dia pertahankan adalah bukti bahwa dia memiliki prinsip. Pemahaman agamanya juga cukup kuat. Lakilaki ini sering mengutip ayat dari kitab sucinya, atau

Analisis Nilai Aqidah Pada Novel Surga Yang Tak Dirindukan Karya Asma Nadia 
perkataan Nabi, saat menerangkan konsep Islam tentang istri, rumah tangga, dan lain-lain" $\quad(S Y T D R$ : 166).

Kutipan di atas menunjukkan

keyakinan Luki Hidayat yang menjadikan kitab suci sebagai pedoman hidupnya. Allah menurunkan Kitab suci kepada utusan-Nya untuk di jadinkan pedoman hidup di dunia agar menuntun manusia ke agama yang benar. Hal ini lah yang membuat Luki Hidayat yakin tentang prinsip hidup yang dijalaninya.

\section{Kutipan-kutipan tentang}

Iman kepada Para Nabi dan

Rasul Allah dalam novel Surga

\section{Yang Tak Dirindukan karya}

\section{Asma Nadia}

"Laki-laki yang jatuh cinta melakukannya karena dengan begitu mereka menolong dirinya sendiri agar tak jatuh pada perzinaan. Analisis Nilai Aqidah Pada Novel Surga Yang Tak Dirindukan Karya Asma Nadia
Kecuali di zaman Rasul, Arini sulit melihat bagaimana laki-laki yang berpoligami saat ini mampu bersikap adil. Kenyataannya, keadilan yang seharusnya menjadi prasyarat bagi lelaki untuk mengambil istri lagi, nyaris keluar dari agenda mereka. Arini punya banyak contoh tentang itu" (SYTDR: 113).

Kutipan di atas menunjukkan keyakinan Arini tentang semua hal yang dilakukan Nabi dan Rasul menjadi pedoma bagi manusia. Tapi bagi Arini kenyataan itu jauh kebanyakan lelaki memilih menikah lagi hanya untuk dirinya sendiri memuaskan hawa nafsunya, agar terlepas dari perzinaan.

\section{Kutipan-kutipan tentang}

Iman kepada Qadha dan Qadar

Allah dalam novel Surga Yang

Tak Dirindukan karya Asma

Nadia. 
"Kebahagiaan akan datang pada masanya, komentarnya dulu. Arini percaya takdir. Dengan keyakinan itu dia telah melewati ribuan hari. Kadang memang keingintahuan menggelitiknya. Pangeran mana yang akan Allah kirimkan padanya, bila memang kesempatan itu ada sebelum dia menjadi tawanan kematian?" (SYTDR: 9).

Kutipan di atas menunjukkan keyakinan Arini akan ketentuan yang Allah berikan. Allah sudah menentukan hidup makhluk-Nya, mulai dari rezeki, kematian, dan jodoh. Untuk itu Arini pasrahkan semuanya kepada Allah SWT. Arini percaya kepada takdir yang sudah digariskan Allah untuknya, yaitu takdir mengenai pasangan hidup.

PENUTUP

Setelah dilakukan penelitian ditemukanlah aspek-aspek nilai aqidah yang paling banyak pada novel Surga

Yang Tak Dirindukan karya Asma

Nadia adalah aspek iman kepada

Allah. Bila kita mengimani bahwa

Allah SWT adalah satu-satunya Raja yang menguasain alam semesta (bumi langit dan seluruh isinya) maka kita minimal harus mengakui bahwa Allah SWT adalah Pemimpin (Wali), Penguasa yang menentukan (Hakim) dan Yang Menjadi Tujuan (Ghayah). Hal ini sesuai dengan kutipan yang dominan yang terdapat dalam novel Surga Yang Tak Dirindukan karya Asma Nadia, yaitu iman kepada Allah. Semua manusia hanya boleh menyembah Allah dan menjadikanNya tujuan hidup. Tidak ada satu pun yang bisa menolak apa yang menjadi ketetapan Allah. Karena Allah maha kuasa atas segalanya. 


\section{DAFTAR PUSTAKA}

Atmazaki. 2005. Ilmu Sastra dan Terapan. Padang: Yayasan Cipta Budaya Indonesia

Endraswara, Suwardi. 2013. Metodologi Penelitian Sastra; Epistemologi, Model, Teori, dan Aplikasi. Yogyakarta: CAPS (Center for Academic Publishing Service).

https://referensibukubagus.wordpress. com/2014/06/24/resensibuku-surga-yang-takdirindukan-by-asmanadia. (Diakses 09-Ferburuari2016).

Ilyas, Yunahar. 1993. Kuliah Aqidah Islam. Universitas Muhammadiyah Yogyakarta: LPPI (Lembaga Pengkajian dan Pengalaman Islam).

Kosasih, E. 2012. Dasar-dasar Keterampilan Bersastra. Bandung: Cv Yrama Widya.

Munir, A dan Sudarsono. 2013. Dasar-dasar Agama Islam. Jakarta: PT Rineka Cipta.

Nadia, Asma. 2104. Surga Yang Tak Dirindukan. Depok: AsmaNadia Publishing House.
Nurgiyantoro, Burhan. 2013. Teori Pengkajian Fiksi. Yogyakarta: Gadjah Mada University Press.

Purba, Antilan. 2010. Sastra Indonesia Kontemporer. Yogyakarta: Graha Ilmu.

Rafiek, M. 2012. Teori Sastra; Kajian Teori dan Praktik. Bandung: PT Refika Aditama.

Rokhmansyah, Alfian. 2014. Studi dan Pengkajian Sastra; Perkenalan Awal Tahapan Ilmu Sastra. Yogyakarta: Graha Ilmu.

Semi, Atar. 2012. Metode Penelitian Sastra. Bandung: Angkasa.

Siswantoro. 2010. Metode Penelitian Sastra; Analisis Struktur Puisi. Yogyakarta: Pustaka Belajar.

Susanto, Dwi. 2016. Pengantar Kajian Sastra. Yogyakarta: CAPS (Center for Academic Publishing Service).

Teeuw. A.2003. Sastra dan Ilmu Sastra. Jakarta: PT Dunia Pustaka Jaya.

Wiyatmi. 2012. Kritik Sastra Feminis. Yogyakarta: Ombak (Anggota IKAPI) 